\title{
Electron Microscopic Studies on Black Lines Appearing in Muscle Tissues of Cultured Red Sea Bream Pagrus major
}

\author{
Kuniko Wakazono, ${ }^{* 1}$ Yasuo Okajima, ${ }^{* 1}$ Masataka Shirai, ${ }^{* 1}$ \\ Chikara Kitajima, *2 Seiichi Matsui,*? \\ Toshiyuki Tanabe, ${ }^{* 2}$ and Jiro Matsumoto*3 \\ (Received February 24, 1992)
}

\begin{abstract}
The dorsal muscles of the red sea bream Pagrus major, when reared in an outdoor tank, become marked with numerous black lines. The darkish appearance of these tissues has been known to be markedly improved upon rearing in dark conditions for three months. In this study, we examined (1) cytological properties of the black lines, (2) their changes under dark adaptation and (3) possible implication of acid phosphatase in paling or depigmentation processes using transmission electron microscopy and its associated cytochemistry. The results indicate that (1) the black lines distributed along the blood vessels in muscles of the fish reared in an unshaded outdoor tank are composed of a large number of fully differentiated melanophores, each stretching melanosome-laden cytoplasmic processes; (2) the melanophores in the muscles of dark-adapted fish appear as a collapsed mass of melanosomes, indicating that they are in an aggregated state; (3) no apparent difference is observed in acid phosphatase activity between light- and darkadapted fish.

The similar population density of melanophores in the periphery of the blood vessels between the light- and dark-adapted fish strongly suggests that paling of the muscie tissues induced by dark adaptation results from melanosome aggregation in these cells, and not from a marked decrease of melanophores.
\end{abstract}

It has been known that muscle tissues (white muscles) of the cultured red sea bream Pagrus major, when raised in a shallow outdoor tank or a net-cage in the sea, become marked with many black lines, not seen in those of wild fish, ${ }^{1)}$ and that these black lines are composed of numerous melanophores. ${ }^{2}$ The conspicuous unfamiliar appearance of muscles in these cultured fish has markedly reduced their market value, causing disadvantages to their breeders. Due to the absence of exact information on the nature of the black lines, little adequate action has so far been taken for outdoor cultivation of these fish.

Recent macroscopic examination has disclosed that the black lines in these muscle tissues are composed of a melanin-like substance distributed along the blood vessels. ${ }^{2)}$ Trials to shade these fish from the sunshine with a black net have resulted in a marked decrease in black lines of these muscle tissues. ${ }^{2)}$ The objective of this study is to characterize the morphological and cytological properties of the black lines appearing in the muscle tissues of cultured sea bream by means of transmission electron microscopy.

\section{Material and Methods}

\section{Source and Rearing Condition of Fish}

The fish used in this study were one-year-old red sea bream obtained from a commercial breeder. Groups of fifty fish with an average total body length of $150 \mathrm{~mm}$ were reared for 3 months (September to December, 1989) in two 2-kiloliter circular concrete tanks in the Fishery Research Laboratory of Kyushu University: one was kept under natural light conditions while the other was kept under dark conditions in

*1 Mercian Corporation, Central Research Laboratories, Jonan, Fujisawa, Kanagawa 251, Japan (若罍邦子, 阙帛筷夫，白井正䓔：メルシャン(株) 中央研究所).

*2 Fishery Research Laboratory, Kyushu University, Tsuyazaki, Fukuoka 811-33, Japan (北息 力, 松井

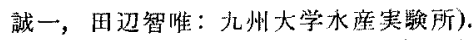

*3 Department of Biology, Keio University, Hiyoshi, Kohoku, Yokohama, Kanagawa 223, Japan (烃本二郎: 慶応義熟大学生物学教空). 


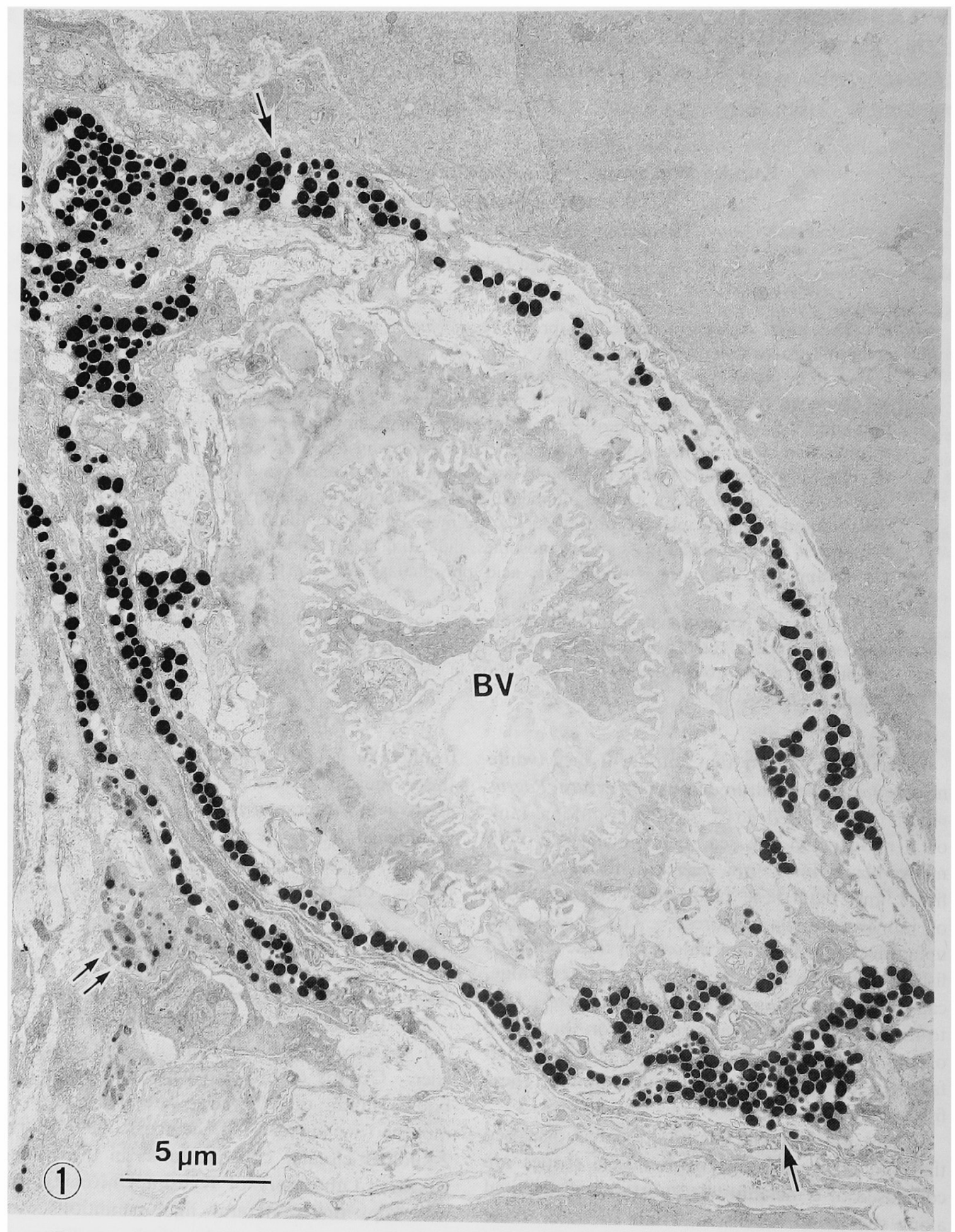

Fig. 1. A cross section of black lines appearing in the dorsal muscles of a red sea bream reared in an outdoor tank under natural light condition. The blood vessel (BV) is surrounded by several melanophores $(\rightarrow$ ) with long extended cytoplasmic processes. Each melanophore contains numerous, fully melanized melanosomes which spread out almost homogeneously over the entire cytoplasm, even in the tip of the process. In the vicinity of melanophores, there are a few macrophage-like cells $(\rightrightarrows)$ which include melanosomes inside. $(\times 1,800)$. 
which sunshine was shaded totally with a black vinyl sheet (screening rate: $100 \%$ ).

Fish were fed with commercially available fish food every day and raised in a tank filled with fresh sea water running at a rate of $1 \mathrm{t} / \mathrm{h}$. At the end of the rearing, four fish were randomly selected from each group, killed by decapitation, and then subjected to dissection of black linerich regions of the dorsal muscles. For comparison, small pieces of dorsal skin and fin were also dissected from the same fish. Two living wild red sea bream of similar size, which had been captured in the sea, were also subjected to tissue sampling in the same way as mentioned.

\section{Electron Microscopy}

Small pieces of muscle, skin, and fin tissues were cut out from the dorsal trunk with the use of a razor blade, prefixed in $2.5 \%$ glutaraldehyde in $0.1 \mathrm{M}$ cacodylate buffer $(\mathrm{pH} 7.4)$ at $4^{\circ} \mathrm{C}$ and then postfixed in $1.0 \%$ osmium tetroxide in the same buffer. After being processed in a graded series of ethanol using $25 \%$ (15 min), $50 \%$ (15 min), $80 \%$ (15 min), $90 \%$ (15 min), $95 \%$ (overnight), $99 \%$ (15 min), and $100 \%$ (15 min three times), they were embedded in Quetol 812 and cured at $60^{\circ} \mathrm{C}$. Ultrathin sections were cut on an LKB ultramicrotome and stained with uranylacetate and lead citrate, and examined with a JEM $1200 \mathrm{EX}$ electron microscope at $80 \mathrm{KV}$ accelerating voltage.

\section{Acid Phosphatase Assay}

The assay was performed according to the procedure adopted by Hori et al. ${ }^{3)}$ Small pieces of tissue were fixed in $2.5 \%$ glutaraldehyde in $0.1 \mathrm{M}$ sodium phosphate buffer for $30 \mathrm{~min}$ at $4^{\circ} \mathrm{C}$ and, after a brief rinse in phosphate buffer, were incubated in modified Gomori's assay medium for $60 \mathrm{~min}$ at $37^{\circ} \mathrm{C}$. Tissues thus treated were refixed in $2.5 \%$ glutaraldehyde in the same buffer briefly and then in $1.0 \%$ osmium tetroxide, followed by embedding in Quetol 812. Further treatment of the specimens was carried out in the same way as for the ordinary electron microscopy.

\section{Results}

Electron microscopic examinations on black line-rich regions of dorsal muscle tissues of red sea bream reared under natural light conditions disclosed that a number of typical melanophores were distributed along the blood vessels and

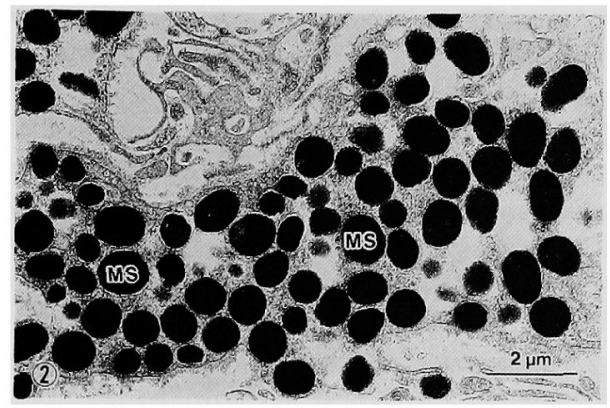

Fig. 2. An enlarged portion of Fig. 1 indicating a close-up view of melanosomes (MS). Melanosome is round to ellipsoidal in shape, approximately $0.5 \mu \mathrm{m}$ in diameter, is delimited by the unit membrane, and contains dense material (melanin) inside. Note that there are only a few common cytoplasmic organelles such as elements of endoplasmic reticulum. $(\times 9,000)$.

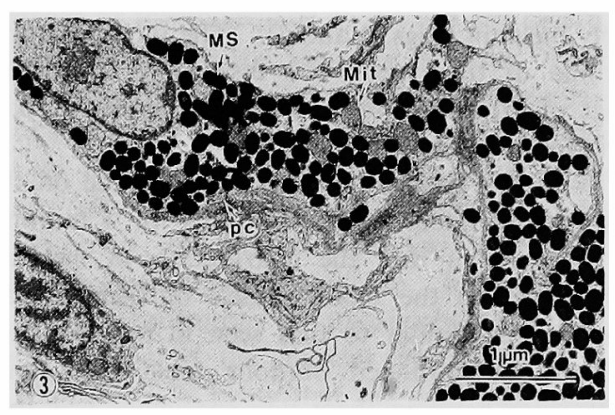

Fig. 3. An image of integumental melanophores in a red sea bream reared in an outdoor tank under natural light conditions. A longitudinal section of the dorsal fin. The general appearance of these cells is essentially similar to that present in Figs. 1 and 2, except for relatively frequent occurrence of mitochondria (Mit) among melanosomes (MS) and pinocytotic vesicles (pv) along the plasma membrane. $(\times 4,500)$.

that their long-projected cytoplasmic processes were covering the outer surface of these organs in the form of a black sheath (Fig. 1). All the melanophores were marked with an abundance of fully melanized melanosomes over the entire cytoplasm, indicating that they were in a fully dispersed state in terms of their physiological motile response (Figs. 1 and 2), ${ }^{4,5}$ Less frequent occurrence of common cytoplasmic organelles in these cells, such as mitochondria and smooth and rough endoplasmic reticulum, indicated that they were terminally differentiated (Fig. 2). ${ }^{8}$ ) Melanosomes found in these melanophores were round to ellipsoidal in shape, approximately 


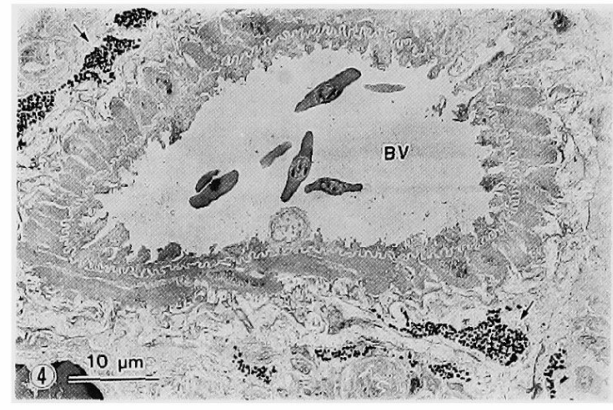

Fig. 4. A cross section of a black line appearing in the dorsal muscles of a red sea bream reared in an outdoor tank under dark conditions, Melanophores $(\rightarrow)$ distributed along the periphery of the blood vessel (BV) appear as collapsed masses of melanosomes. $(\times 1,200)$.

$0.5 \mu \mathrm{m}$ in diameter, delimited by unit membrane, and contained an electron-dense substance, probably melanin (Figs. 2 and 3). The ultrastructural profile of these cells was essentially similar to that of melanophores present in the dorsal skin and fin of the fish (Fig. 3).

When the same examination was made on the fish reared under dark conditions for 3 months, it was shown that the distribution of melanophores along the blood vessels of their muscle tissues was similar to that seen in the fish kept in an unconditioned outdoor tank. The only difference between these two specimens was that the melanophores appeared as collapsed bodies of an irregular shape (Fig. 4). A cross sectional low-power image of the blood vessels appeared as coaxial circles of a blood vessel and an outer collagenous sheet containing black corpuscles. A close observation of these melanophores disclosed that such a cell profile was formed by simultaneous aggregation of their melanosomes toward the cell center. Thus, it was apparent that melanophores present in the dark-adapted fish were in an aggregated state. In the light-adapted, tank-reared fish, melanophores in the skin and fin were mostly in a dispersed state, whereas in the dark-adapted ones, these cells exhibited either an aggregated or intermediate or occasionally diapersed state. It was presumed that an inconstant state of pigmentary responses in the latter may be caused by tissue-handling processed in light conditions.

The number of melanophores distributed near the blood vessels of the light- and the darkadapted fish on electron micrographs indicated that there was little difference with regard to their

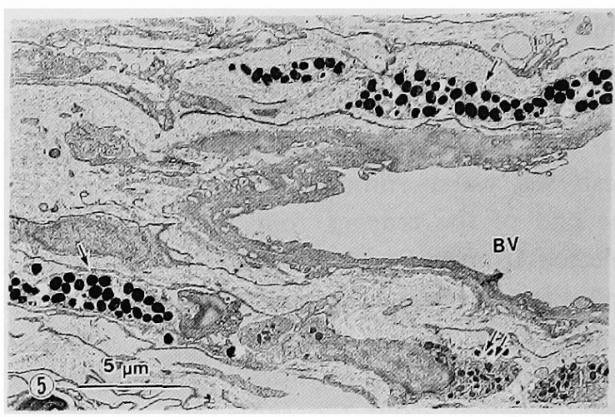

Fig. 5. An image of melanophores appearing in the dorsal muscle of a wild red sea bream. The population density of melanophores $(\rightarrow)$ near the blood vessel (BV) in the wild fish is much smaller than that in the experimentally reared ones. Macrophage-like cells $(\overleftrightarrow{\rightarrow})$ are also distributed experimentally in the position (adventitia) where a large number of melanophores are distributed in the cultured fish. $(\times 1,900)$.

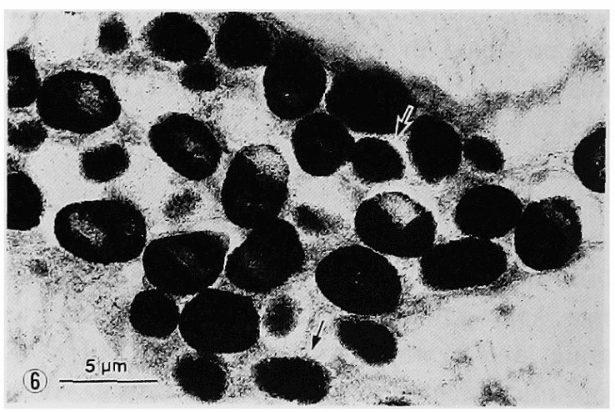

Fig. 6. A portion of melanophores assayed for acid phosphatase activity. Note that reaction products $(\rightarrow)$ are distributed as fine dots around the contour of melanosomes. This picture is an enlarged image of the cells present near the blood vessel of muscle tissue in the red sea bream reared in natural light conditions. $(\times 18,000)$.

population density.

Judging from the similarity in morphological profile and population density of melanophores between the two groups of tank-reared, experimentally treated fish, it seems reasonable to presume that the presence or absence of macroscopically detectable black lines in the dorsal muscles of the tank-reared red sea breams under different lighting conditions resulted from dispersion or aggregation of melanosomes within the cells.

When the wild fish of this species serving as the control were examined, it was apparent, as far as compared with several electron micrographs of a cross section of the blood vessels, that the number of melanophores distributed 
near the blood vessels of muscle tissues was much fewer than that in the tank-reared, experimentally tread fish (Fig. 5).

Electron microscopic cytochemical assay of acid phosphatase disclosed that reaction products were deposited in a detectable amount along the fringe of the melanosomes distributed over the melanophores of dorsal muscle tissues of lightadapted red sea bream (Fig. 6). Due to heavy melanization of melanosomes, it became difficult to observe the deposition of such reaction products within their matrices. The comparison between muscle tissues from two groups of fish reared under light or dark conditions indicated that there was little difference with respect to the distribution of reaction products.

\section{Discussion}

The present study clearly indicated that black lines appearing in the dorsal muscles of cultured red sea bream were melanophores aligned along the blood vessels of these tissues. Electron microscopic observations indicated that such melanophores contained numerous densely melanized melanosomes. As for the difference in the appearance of muscle tissues between the light- and dark-adapted fish, this was considered to be mainly associated with the state of melanosome distribution within melanophores. In the light-adapted fish, all the melanophores appeared in a dispersed state, spreading their melanosomes out over the entire cytoplasm, whereas in the dark-adapted fish, these cells appeared in an aggregated state, collapsing their melanosomes around the cell center. These findings would indicate that melanophores present in muscle tissues are capable of motile response depending upon light conditions as integumental melanophores, even though the exact mechanism for controlling motile response of melanophores in this species is unknown. ${ }^{\text {) }}$ Viewing from an almost equivalent number of melanophores around the blood vessels in the light- and darkadapted fish, it was likely that dark adaptation brings about a paling effect or a decrease of black lines. It is well known that in amphibians whose pigmentary responses are under hormonal regulation, long-sustained melanophore aggregation is closely associated with the loss of melanin pigment or morphological paling. ${ }^{\left.{ }^{2}\right)}$ Inability of the melanophores in muscle tissues of the red sea bream to respond to potassium chloride ${ }^{2}$ strongly suggested an absence of innervation of these cells, thus suggesting that the melanophores present in the muscle tissues of these fish are under hormonal control, though the nature of the hormone(s) remains to be resolved. Inability to detect acid phosphatase activity in the darkadapted fish would support the fact that disintegration of melanosomes in the melanophores was not active or was extremely slow.

It is well known that skin melanophores in fish are derived from the neural crest which appears during embryonic development. ${ }^{\mathrm{B}}$ ( Melanophores found in the periphery of the blood vessels in muscle tissues are also known to be of the same origin. A marked increase in the number of mealanophores in cultured fish may result from their exposure to stronger light under culture, as seen in the summer flounder. ${ }^{8)}$ Probably, UVB in sunlight plays a key role in the induction of melanogenesis in the red sea bream, as demonstrated in the Japanese flounder. ${ }^{10)}$ It is uncertain whether melanogenesis in the muscles of red sea bream is elicited as a direct effect of the light on the preexisting precursor cells, or as its indirect effect which becomes effective through the secretion of certain hormone(s) such as melanophore-stimulating hormone. Judging from the dense distribution of melanophores in the dorsal portion of the muscles as compared to the ventral, ${ }^{2)}$ it is likely that the light has, more or less, some direct stimulating effect on melanophores or their precursors, causing an increase in their population.

The present paper indicates that dark adaptation of the fish caused melanosome aggregation within melanophores, thus making the appearance of their muscles much closer to that of wild ones. It is widely accepted in lower vertebrates that long-term exposure of animals to dark conditions results in the paling of the body coloration. ${ }^{\text {r) }}$ However, this study provides the first observation that a similar motile response occurs even in melanophores distributed over internal organs such as muscles. In this study, it is shown that dark adaptation for recovering the natural appearance of muscles, as far as examined on the basis of rough observations, requires the duration of almost three months and that even this treatment failed to cause a marked decrease in the number of melanophores. It will be interesting to know whether prolonged dark adaptation of the fish finally restores melanophore distribution as observed in wild fish. 
It is known that acid phosphatase is associated with the degradation of melanosomes, mostly appearing in association with aoutophagosomelike structures in mammalian tissues. ${ }^{3)}$ In fish, it is considered that melanophores are destroyed by macrophage-like cells through phagocytosis. ${ }^{11}$ Inability to detect a high activity of this enzyme in the melanophores of a dark-adapted fish would imply that these cells are not subject to autophagocytotic disintegration. In this connection, it is interesting to note that a number of peculiar cells, probably a kind of phagocytes, appear near the blood vessels of the dark-adopted fish.

Inasmuch as melanophores in general have the ability to stay in tissues longer after their differentiation, it would seem vital that breeders take necessary measures, if discovered, to prevent excess melanophore differentiation at an earlier stage of hatchery breeding.

\section{References}

1) K. Tachibana and M. Tsuchimoto: Mariculture technology, Red sea bream, in "Price formation and quality control of mariculture product" (ed. by K. Hirayama), Koseisha. Koseikakı, Tokyo, 1991, pp. 48-54.
2) S. Matsui, T. Tanabe, M. Furuichi, and T. Kitajima: Studies on clearance of black lines in muscle of cultured fish-I. Nippon Suisan Gakkaishi, 58, 1459-1464, (1992).

3) Y. Hori, K. Toda, M. A. Pathak, W. H. Clark Jr, and T. B. Fitzpatrick: A fine-structure study of the human epidermal melanosome complex and its acid phosphatase activity. $J$, Uttrastr. Res., 25, 109-120 (1968).

4) R. Fujii: Chromatophores and pigments. In Fish phyosiology 3 (ed. by W. S. Hoar and D. J. Randall), Academic Press, New York, 1969, pp. 307-353.

5) D. Bikle, L. G. Tíney, and K. R. Porter: Microtubules and pigment migration in the melanophores of Fundulus heteroclitus. Protoplasma, 61, 322-345 (1966).

6) W. A. Turner $J_{r}$, J. D. Taylor, and T. T. Tchen: Melanosome formation in the goldfish: the role of multivesicular bodies, J. Ultrastr. Res., 51, 16-31 (1975).

7) J. T. Bagnara and M, E. Hadley: Chromatophores and color change. Prentice-Hall. Inc. Englewood Clifs, N. J., 1973 , pp. 74-97.

8) G. L. Orton: Development and migration of pigment celis in some teleost fishes. J. Morph, 93, 69-100 (1953).

9) C. M. Osbon: Studies on the growth of integumentary pigment in the lower vertebrates. I. The origin of artificially developed melanophores on the normally unpigmented ventral surface of the summer flounder (Paralichthys dentatus). Biol. Bull, 81, 341-351 (1941).

10) J. Matsumoto and T. Ishii: Induction of melanophore development in plaice juveniles by ultraviolet irradiation, in "Structure and Function of Melanin" (ed. by K. Jimbow), Fujishoin Co. Ltd., Sapporo, 1986, pp. 75-81.

11) I. K. Takeuchi and T. Kajishima: Fine structure of goldish melanophages appearing in the depigmentation process, Annot. Zool. Japon., 46, 77-84 (1973). 